\title{
Cold-Sprayed Aluminum-Silica Composite Coatings Enhance Antiwear/Anticorrosion Performances of AZ31 Magnesium Alloy
}

\author{
Lijia Fang, ${ }^{1,2}$ Yuting Xu, ${ }^{2}$ Li Gao, ${ }^{1}$ Xinkun Suo $\mathbb{D}^{2},{ }^{2}$ Jianguo Gong, ${ }^{1}$ and Hua Li $\mathbb{D}^{2}$ \\ ${ }^{1}$ Qinghai Provincial Key Laboratory of New Light Alloys, School of Mechanical Engineering, Qinghai University, \\ Xining 810016, China \\ ${ }^{2}$ Key Laboratory of Marine Materials and Related Technologies, Zhejiang Key Laboratory of Marine Materials and Protective \\ Technologies, Ningbo Institute of Materials Technology and Engineering, Chinese Academy of Sciences, Ningbo 315201, China \\ Correspondence should be addressed to Xinkun Suo; suoxinkun@nimte.ac.cn
}

Received 10 September 2017; Accepted 19 November 2017; Published 6 May 2018

Academic Editor: Aniello Riccio

Copyright (c) 2018 Lijia Fang et al. This is an open access article distributed under the Creative Commons Attribution License, which permits unrestricted use, distribution, and reproduction in any medium, provided the original work is properly cited.

\begin{abstract}
Extensive efforts devoted in recent years to booming structural applications of lightweight magnesium alloys are usually undermined by their insufficient surface properties. Surface modification is therefore necessarily required in most cases for enhanced surface integrity of the alloys. Here, we report construction of aluminum-silica protective layers by cold spray on AZ31 magnesium alloys, and the effect of the silica additives on microstructure and mechanical properties of the coatings was examined. The ceramic particles were dispersed evenly in the coatings, and increased silica content gives rise to enhanced adhesion, antiwear performances, and microhardness of the coatings. The even distribution of silica in the coatings altered the wear regimes from adhesive to abrasive wear. The cold spray fabrication of the aluminum-silica protective coatings would facilitate structural applications of the magnesium alloys.
\end{abstract}

\section{Introduction}

Magnesium alloys are promising lightweight materials with extensive applications in automotive, aerospace, and electronics industries. However, challenges persist due to their relatively poor corrosion and wear resistance, which has been one of the major hurdles affecting development of the alloys [1]. One of the most effective solutions to prevent the corrosion is to coat an anticorrosion layer on magnesium alloys. Many surface techniques, such as thermal spraying, chemical vapor deposition, sol-gel, plating, anodizing oxidation, and microarc oxidation, have therefore been attempted to improve the anticorrosion performances of magnesium alloys [2-7], in which it was reported that a thin layer is effective in preventing penetration of corrosive substances. In many cases, corrosion is accompanied by wear for magnesium alloy components; it is therefore essential that the protective layers must simultaneously possess anticorrosion/antiwear performances.

Addition of ceramic materials to alloy-based coating can effectively improve its wear resistance, corrosion resistance, or temperature oxidation resistance $[8,9]$. Lee et al. $[10,11]$, Shkodkin et al. [12], and Irissou et al. [8] reported that incorporating ceramic particles into metallic coatings not only improved the quality of the coatings by reducing their porosity but also increased their bonding strength. Porosity reduction of the coatings contributes to further enhanced corrosion resistance [8]. A variety of ceramics such as $\mathrm{Al}_{2} \mathrm{O}_{3}[10,13]$, $\mathrm{SiC}$ $[14-17]$, and TiN $[18,19]$ have been investigated as the secondary phase in metallic matrix ceramic composites.

As one of the recently developed surface coating techniques, cold spraying differs from the conventional thermal spray methods. During cold spray processing, micron-sized particles are accelerated by an inert gas stream to a high velocity, and the feedstock remains in the solid state throughout the entire processing. This in turn solves the problems associated with high processing temperature, such as chemical reaction, phase transition, oxidation, or unfavorable structural changes. Apart from the advantages of spraying temperature-sensitive materials, cold spray provides the coatings with very dense microstructure [20], giving rise to better mechanical properties and corrosion resistance. For the temperature-sensitive 
magnesium alloy substrates, cold spray might be an appropriate technique for fabricating protective coatings. It has been clear that addition of hard ceramic particles into cold-sprayed coatings remarkably improves their hardness and wear resistance $[12,21]$. In this study, $\mathrm{Al}-\mathrm{SiO}_{2}$ composite coatings were deposited by cold spray on the AZ31 magnesium alloy. The effect of $\mathrm{SiO}_{2}$ content on the microstructure, mechanical properties, and anticorrosion properties of the coatings was examined and elucidated.

\section{Materials and Methods}

2.1. Deposition of Coatings. Spherical commercial pure aluminum powder (Beijing General Research Institute of Mining and Metallurgy, China) with a mean size of $25 \mu \mathrm{m}$ and angular $\mathrm{SiO}_{2}$ powder (Beijing General Research Institute of Mining and Metallurgy, China) with a mean size of $16 \mu \mathrm{m}$ were used in this study. As reported in [22], the ceramic particle can only deposit to form a coating unless it impacts on a metallic surface, and that impacting onto a ceramic surface cannot form a coating. Therefore, the ceramic content in the coating is less than that in the designed original powder. Depending on the nature and the particle size of the ceramic phase, the corresponding relation of the ceramic content in the original power and in the composite coating is different. For the new addition phase $\mathrm{SiO}_{2}$, this corresponding relation is unclear. Therefore, $\mathrm{SiO}_{2}$ particles with different contents from $10 \mathrm{vol} \%$ to $40 \mathrm{vol} . \%$ were added into the powder by mechanical blending. The composite coatings with different $\mathrm{SiO}_{2}$ content were fabricated by cold spraying (CGT KINETIKS 4000, Germany). Nitrogen was used as acceleration gas and carrier gas at the temperature of $350^{\circ} \mathrm{C}$ and the pressure of $3 \mathrm{MPa}$. The spraying distance was $30 \mathrm{~mm}$, and the traverse speed of the gun was $200 \mathrm{~mm} / \mathrm{s}$. The pure $\mathrm{Al}$ coating and composite coatings with 10 vol. $\%, 20 \mathrm{vol} . \%$, and 40 vol. $\% \mathrm{SiO}_{2}$ particles were named as coating 0 , coating 10 , coating 20 , and coating 40, respectively. AZ31 magnesium alloy (AZ31) plates with a dimension of $20 \mathrm{~mm} \times 20 \mathrm{~mm} \times 3 \mathrm{~mm}$ were used as substrates. Prior to spraying, the substrates were surface grit blasted using 60-mesh black fused alumina sands and subsequently degreased by sonication cleaning in acetone.

2.2. Characterization of the Coatings. Phase composition of the powder and the coatings were characterized by X-ray diffraction (XRD, D8 Advance, Bruker AXS, Germany) at a scanning rate of $0.02^{\circ} / \mathrm{s}$ over a $2 \theta$ range of $10^{\circ} \sim 90^{\circ}$ using $\mathrm{Cu}$ $\mathrm{K} \alpha$ radiation operated at $35 \mathrm{~mA}$ and $40 \mathrm{kV}$. Topography and cross-sectional morphology of the coatings were examined by using field emission scanning electron microscope (FESEM, Hitachi S-550N, Japan). Element analyses were carried out by using energy dispersive X-ray spectra (EDX) equipped with FESEM. The porosity of the coating was measured by image analysis, and at least ten images per coating were taken. The microhardness of the coating was measured using a Vickers hardness tester with $100 \mathrm{~g}$ load with dwelling time of $10 \mathrm{~s}$. Five points per sample were acquired randomly to obtain reliable data. Bonding strength of the coating was tested following the ASTM standard C633-01.
The tribological properties of the coatings were evaluated using a reciprocating-type ball-on-disc tribometer (JLTB-02, J\&L Tech Co. Ltd., Korea). The tests were performed under a load of $3 \mathrm{~N}$ for $30 \mathrm{~min}$ at $18.6^{\circ} \mathrm{C}$ with a relative humidity of $70 \%$. Steel balls (1Cr15) with a diameter of $6 \mathrm{~mm}$ were used as the counterparts. The coatings and balls were ultrasonically cleaned in acetone prior to the tests, and a new ball or a new position of the ball was used for each friction test. The friction coefficients and sliding time were automatically recorded during the tests. For each sample, the measurement was repeated three times. Electrochemical impedance spectroscopy (EIS) measurements were performed using a Solartron ModuLab system (2100A, UK). The tests were conducted in $3.5 \mathrm{wt}$.\% $\mathrm{NaCl}$ solution at room temperature. AC signal of $10 \mathrm{mV}$ and the frequency ranging from $100 \mathrm{kHz}$ to $0.01 \mathrm{~Hz}$ were employed. Before the electrochemical measurement, the coating samples were immersed in an aerobic chamber containing $3.5 \mathrm{wt} \% \mathrm{NaCl}$ solution for $30 \mathrm{~min}$. Each measurement was repeated three times.

\section{Results and Discussion}

Figure 1 shows the topographical morphology and cross section of the cold-sprayed coatings produced in this study. As can be seen from Figures 1(a) and 1(b), the pure Al coating and $\mathrm{Al}+\mathrm{SiO}_{2}$ coatings exhibited significantly different surface morphologies. For coating 0 (Figure 1(a)), particles on the top of the coating remained smooth features with only few very small carters that were induced by debonding $\mathrm{Al}$ particles as indicated by white arrows. However, for the composite coating as shown in Figures 1(b)-1(d), the top surface of the coatings was much rougher. Many angular carters can be observed as indicated by white arrows, which were due to the rebound of $\mathrm{SiO}_{2}$ during the coating formation process. For better understanding the deposition features of the coatings, the crosssectional views of the coatings are provided in Figures 1(e) and 1(f). Clearly, composite coating was much denser than pure $\mathrm{Al}$ coating as the rebound $\mathrm{SiO}_{2}$ particles can tamp on the already deposited coating. For quantitative analysis, the porosity and $\mathrm{SiO}_{2}$ content of different coatings are listed in Table 1 . The composite coatings demonstrated much denser structure than the pure $\mathrm{Al}$ coating. In addition, from Table 1, it is also found that the $\mathrm{SiO}_{2}$ content in the coating was lower than that in the original feedstock. Such difference became even larger as the $\mathrm{SiO}_{2}$ content in the feedstock increased. This fact suggests that a large amount of $\mathrm{SiO}_{2}$ particles will rebound during the deposition process.

Figure 2 shows the typical XRD spectra of the coatings and the EDS mapping of the composite coating named as coating 40 . As can be seen from the XRD spectra, all coatings experienced no oxidation during the deposition process, which clearly indicates the advances of cold spray in producing oxide-free coatings. In addition, as the $\mathrm{SiO}_{2}$ content reduced significantly during the deposition process, no $\mathrm{SiO}_{2}$ peaks were detected in the composite coatings. However, from the EDS mapping as shown in Figures 2(b)-2(d), the Si phase was clearly seen in the coating, which indicates the existence of $\mathrm{SiO}_{2}$ in the coating. Also, the $\mathrm{SiO}_{2}$ phase was found to be uniformly distributed in the coating. 


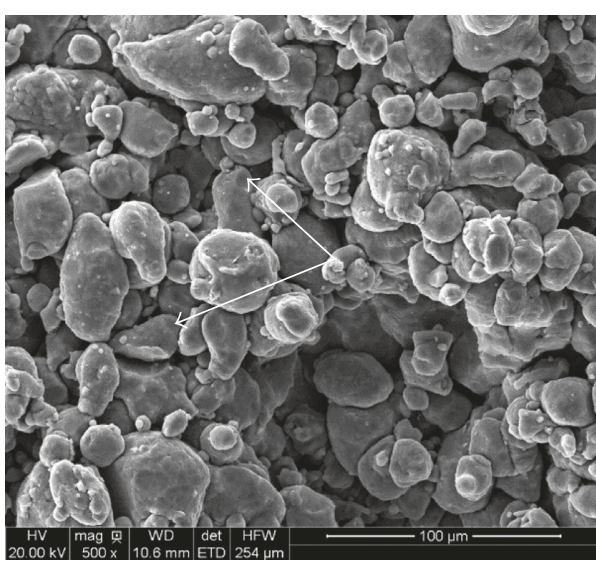

(a)

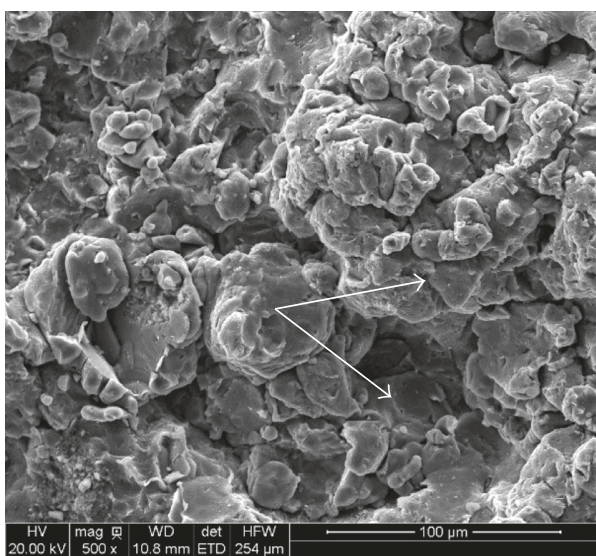

(c)

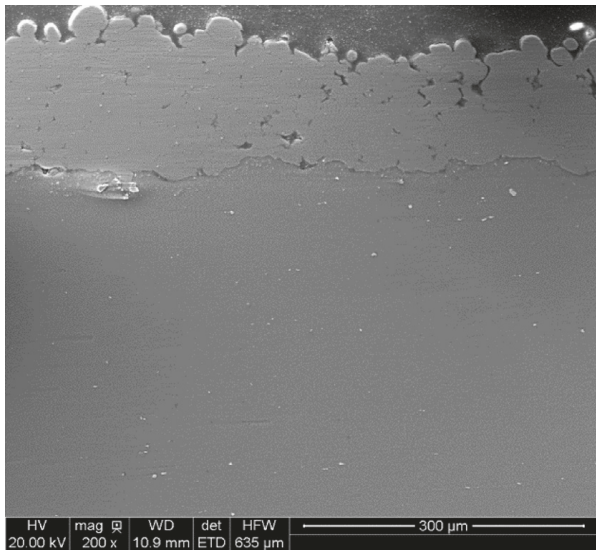

(e)

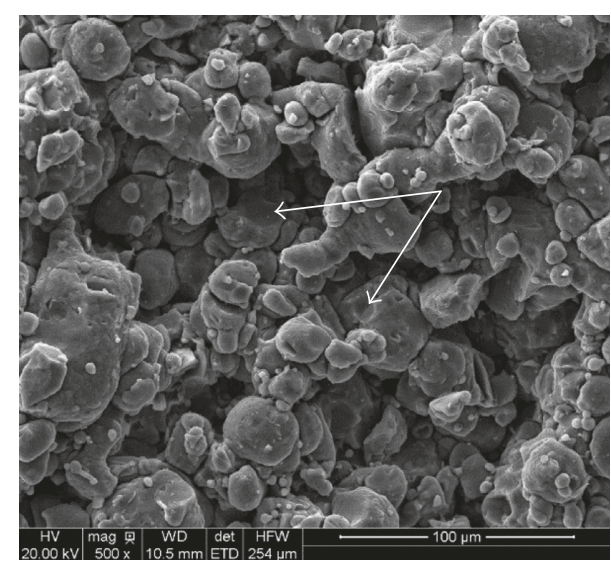

(b)

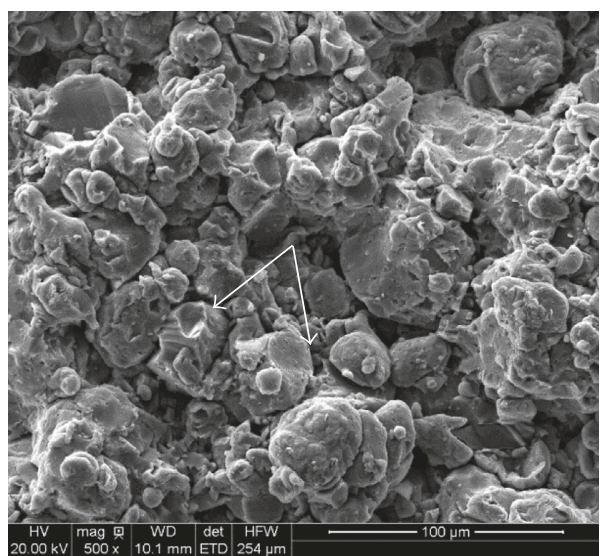

(d)

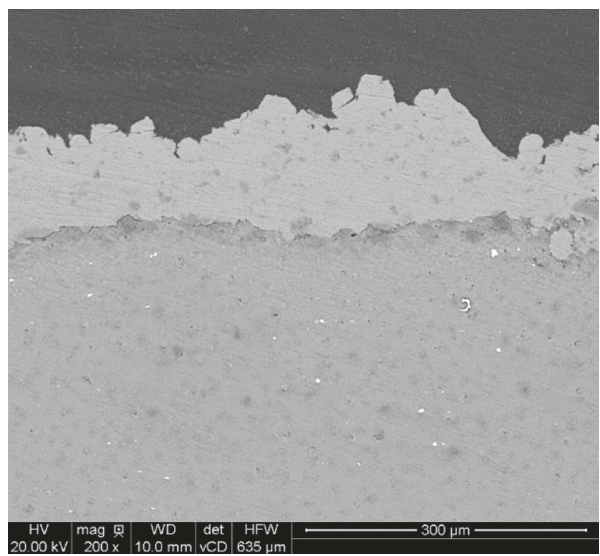

(f)

Figure 1: The surface morphologies of the as-sprayed coating 0 (a), coating 10 (b), coating 20 (c), and coating 40 (d) and the cross-sectional morphologies of coating 0 (e) and the composite coating 40 (f).

TABLE 1: Porosity and $\mathrm{SiO}_{2}$ content of the coatings.

\begin{tabular}{lcc}
\hline Sample & Coating porosity $(\%)$ & $\mathrm{SiO}_{2}$ content $(\%)$ \\
\hline Coating 0 & $5.11 \pm 1.39$ & 0 \\
Coating 10 & $1.23 \pm 0.45$ & $8.98 \pm 0.97$ \\
Coating 20 & $1.33 \pm 0.70$ & $11.46 \pm 1.85$ \\
Coating 40 & $0.77 \pm 0.19$ & $15.75 \pm 1.37$ \\
\hline
\end{tabular}

As for the coating properties, Figure 3 shows the microhardness and adhesion strength of different coatings. It is clearly seen from Figure 3(a) that coating microhardness increased gradually as the $\mathrm{SiO}_{2}$ content increased. The reason for this phenomenon is the increased hard-phase reinforcement. On the one hand, $\mathrm{SiO}_{2}$ itself is much harder than $\mathrm{Al}$ matrix; higher $\mathrm{SiO}_{2}$ content certainly led to higher hardness. On the other hand, increased reinforcement helped to compact the coating and resulted in more work-hardening 


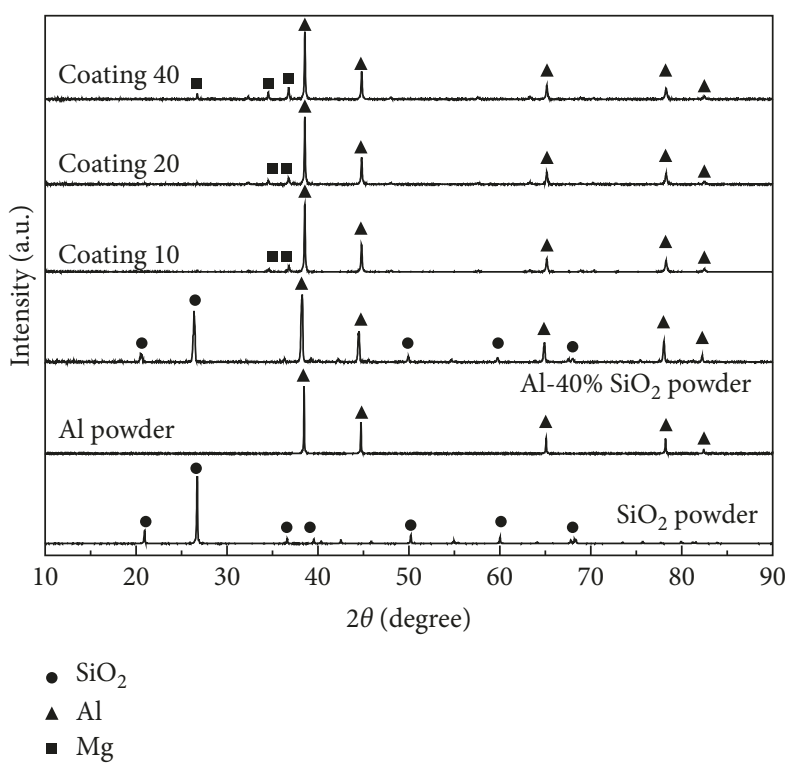

(a)

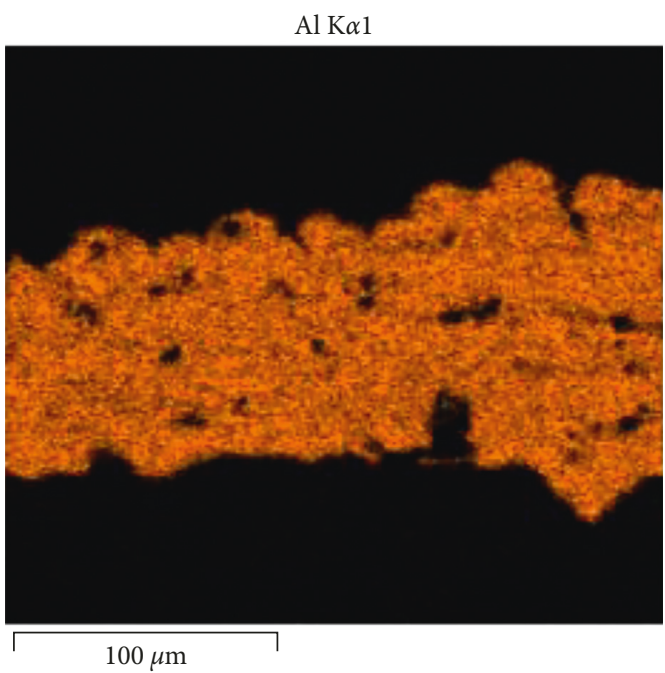

(c)

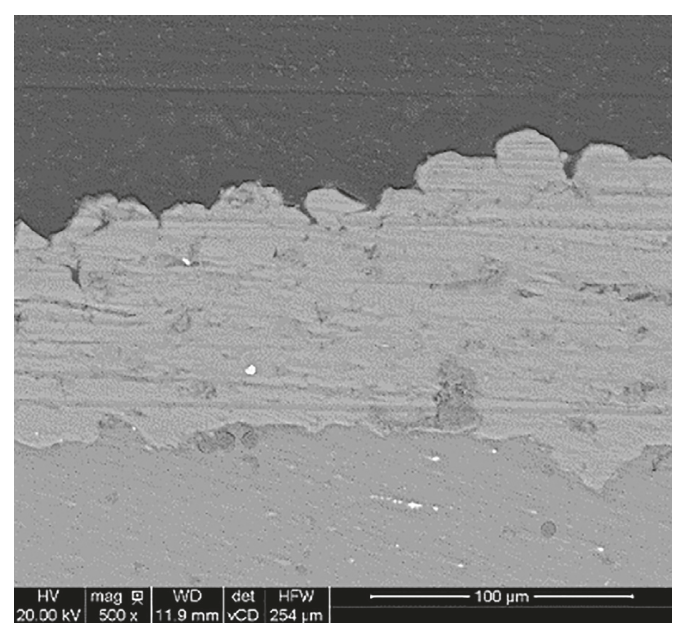

(b)

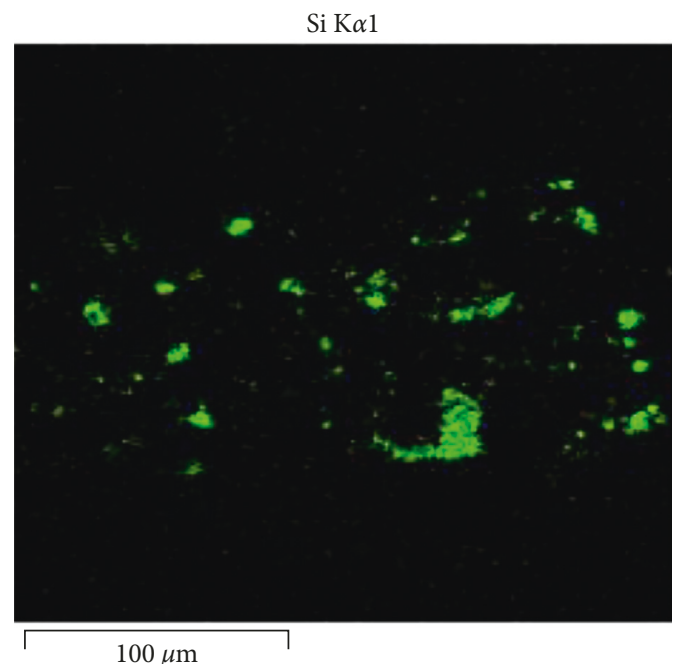

(d)

FIGURE 2: XRD spectra of the powders and the coatings (a) and the typical EDS mapping analysis of the composite coating named as coating $40(\mathrm{~b}-\mathrm{d})$.

effect. Moreover, in Figure 3(b), the adhesion strength of the coating was also found to increase with increasing $\mathrm{SiO}_{2}$ content. This may also be attributed to the compacting effect of the hard $\mathrm{SiO}_{2}$ phase. Increased $\mathrm{SiO}_{2}$ content resulted in the reduction of pores and defects, hence increasing the adhesion strength. Another possible explanation contributing to the increase of the adhesion strength could be the anchor effect of the ceramic particles [23]. However, the interface between the coatings and the substrates did not present significant difference as a function of the ceramic content in the coatings in this investigation. Therefore, the increase of the adhesion strength of the coatings is mainly attributed to the compacting effect of the ceramic particles. The surface roughness of the substrate also influences the adhesion strength of the coating $[24,25]$, which would be investigated in the next study.
The tribological behavior of the coating was also investigated. Figure 4 shows the friction coefficient and wear weight loss of different coatings. It is seen that the friction coefficients of the cold-sprayed coatings were higher as compared with those of the substrate (Figure 4(a)), which may be due to the interior defects and ceramic particles [26-28]. However, it seems that the pure coating and composite coatings had no significant difference in friction coefficient. Furthermore, the weight loss of different coatings as shown in Figure 4(b) indicates that the composite coatings had less weight loss than the pure $\mathrm{Al}$ coating, which clearly demonstrates the wear resistance capability of the $\mathrm{Al}+\mathrm{SiO}_{2}$ composite coatings. For better understanding the wear mechanism, the morphology of the wear surface of the coatings is shown in Figure 5. In Figure 5(a) and 5(b), the 


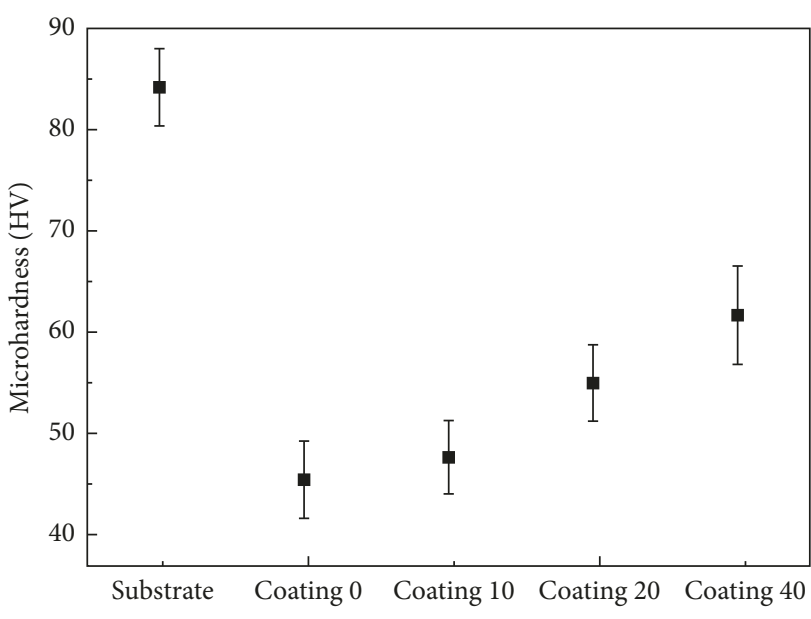

(a)

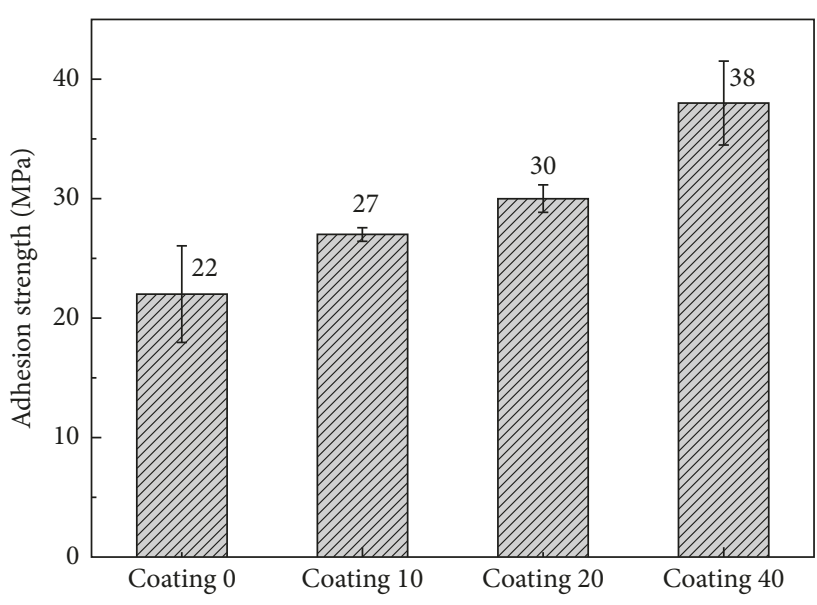

(b)

Figure 3: Microhardness (a) and adhesion strength (b) of the coatings.

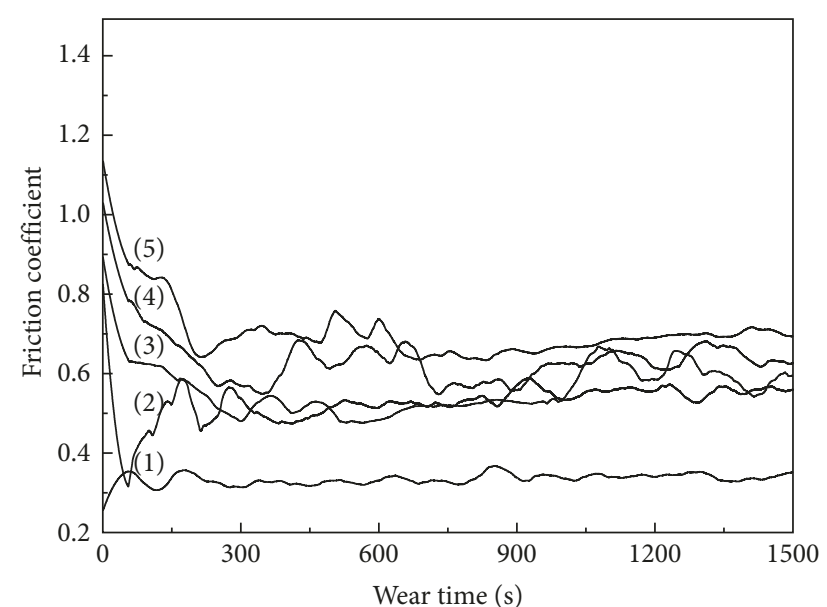

(1) AZ31 Mg

(2) Coating 40

(3) Coating 0

(4) Coating 20

(5) Coating 10

(a)

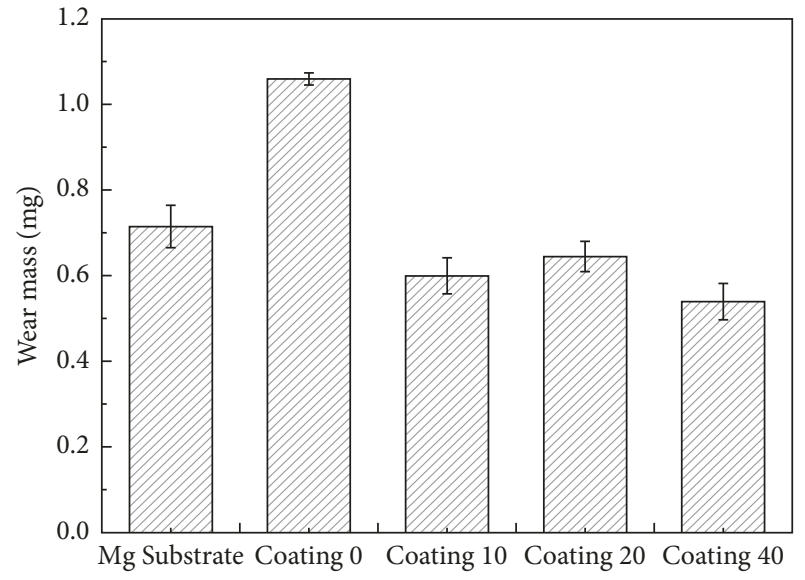

(b)

FIgURE 4: Friction coefficient (a) and wear mass (b) of the substrate and the coatings.

severe delamination of the substrate material and pure $\mathrm{Al}$ coating was observed, indicating the serious wear. However, for the $\mathrm{Al}+\mathrm{SiO}_{2}$ composite coatings, plough and extrusion characterization were found on the wear surface without obvious material delamination phenomenon. This explains why the weight loss of the composite coatings was smaller than that of the pure $\mathrm{Al}$ coating and substrate.

The corrosion behavior of the composite coating was also evaluated by potentiodynamic polarization technique. Figure 6 shows the polarization curves, corrosion potential, and corrosion current density of the different coatings. As can be seen, the current density of the composite coating is much lower than that of the Mg alloy substrate. The corrosion potential of the composite coating shifts toward positive. Both results suggest that $\mathrm{Al}+\mathrm{SiO}_{2}$ composite coating had better corrosion resistance. Moreover, it is also found that the corrosion current density of the composite coating presents a decreasing trend as the ceramic content of the coating increases. The corrosion potential also shifts to positive with the increase of the ceramic content in the composite coating. The increase of the corrosion resistance of the composite coating with a higher ceramic content could be attributed to the decrease of the coating porosity. As shown in Table 1, the porosity of the coating decreases as the ceramic content in the composite coating increases.

\section{Conclusions}

For preventing $\mathrm{Mg}$ alloy from serious corrosion, $\mathrm{Al}$ and $\mathrm{Al}+\mathrm{SiO}_{2}$ composite coatings were fabricated on the AZ31 


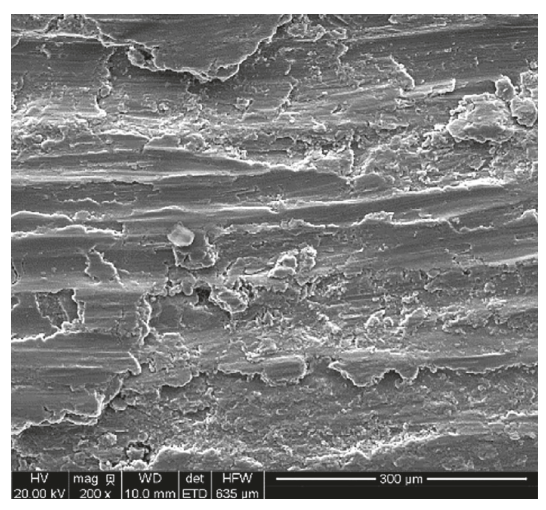

(a)

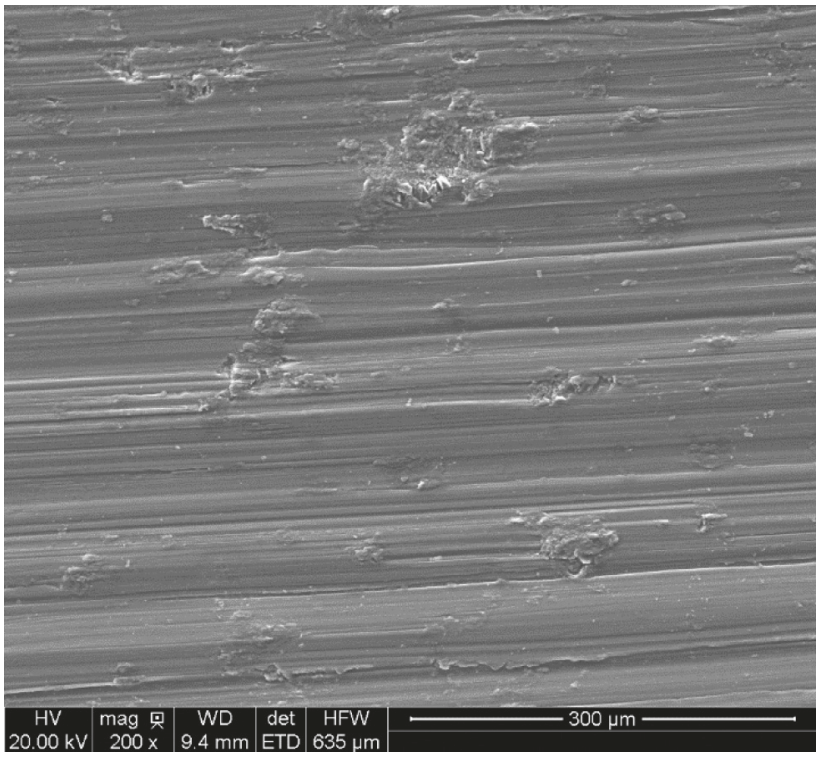

(d)

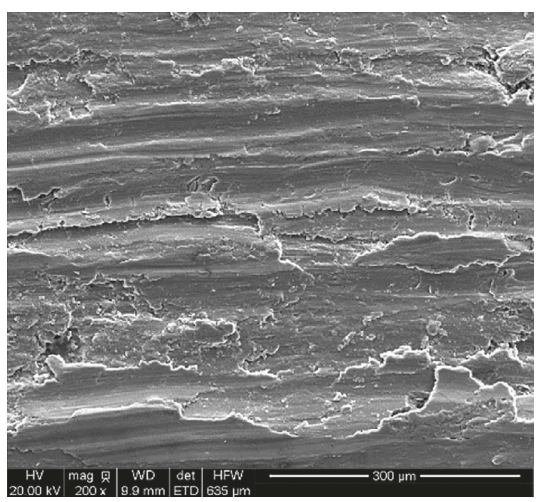

(b)

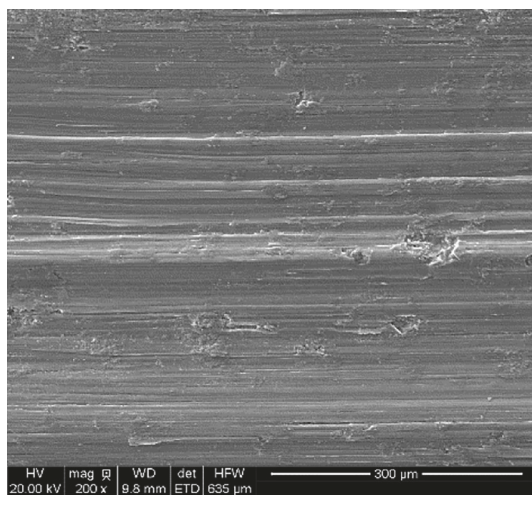

(c)

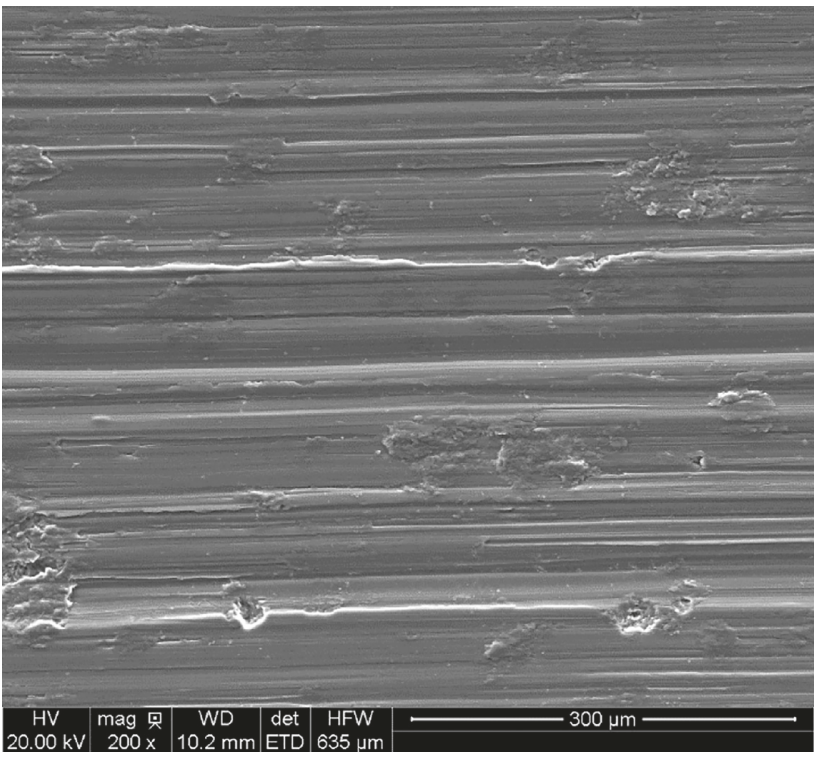

(e)

Figure 5: The typical wear track of the AZ31 magnesium alloy substrate (a), coating 0 (b), coating 10 (c), coating 20 (d), and coating 40 (e).

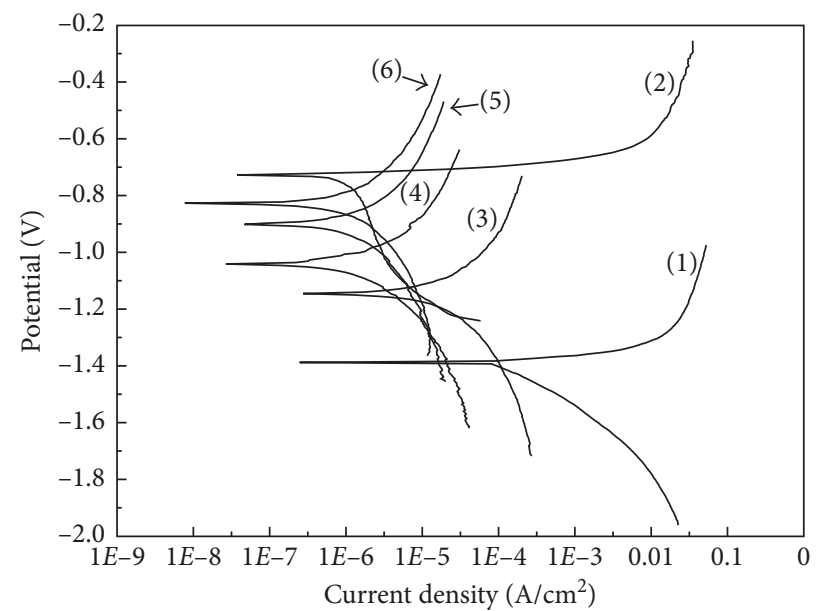

\begin{tabular}{lcc}
\hline Samples & $\begin{array}{c}\text { Corrosion potential } \\
\left(E_{\text {corr }}\right)(\mathrm{V} / \mathrm{SCE})\end{array}$ & $\begin{array}{c}\text { Corrosion current density } \\
\left(I_{\text {corr }}\right)\left(\mathrm{A} / \mathrm{cm}^{2}\right)\end{array}$ \\
\hline AZ31 substrate & -1.387 & $8.796 \times 10^{-5}$ \\
Bulk pure Al & -0.7276 & $7.335 \times 10^{-7}$ \\
Coating 0 & -1.146 & $5.79 \times 10^{-6}$ \\
Coating 10 & -1.04 & $6.66 \times 10^{-7}$ \\
Coating 20 & -0.9 & $6.04 \times 10^{-7}$ \\
Coating 40 & -0.826 & $4.87 \times 10^{-7}$ \\
\hline
\end{tabular}
(1) AZ31
(4) Coating 10
(2) Bulk Al
(5) Coating 20
(3) Coating 0
(6) Coating 40

(a)

(b)

Figure 6: Potentiodynamic polarization curves and electrochemical characteristics of the substrates and the coatings. 
magnesium alloy substrate by cold spraying. The results suggest that the $\mathrm{Al}-\mathrm{SiO}_{2}$ composite coatings had higher performances than the pure $\mathrm{Al}$ coating. The composite coatings showed higher density, microhardness, bonding strength, wear resistance, and corrosion resistance. The content of $\mathrm{SiO}_{2}$ particles in the coatings had no significant effects on the coating properties. Moreover, $\mathrm{SiO}_{2}$ was found to significantly reduce in the coatings as compared with that in the feedstock due to the rebounding during the deposition. With the addition of $\mathrm{SiO}_{2}$ particles, the wear mechanism transfers from adhesive wear to abrasive wear.

\section{Conflicts of Interest}

The authors declare that they have no conflicts of interest.

\section{Acknowledgments}

This study was supported by the Natural Science Foundation of China (21705158), Fundamental Research Project of Qinghai Province (2016ZJ757), Project of Scientific Innovation Team of Ningbo (2015B11050), National Key Research and Development Program of Zhejiang Province (2015C01036), International Scientific and Technological Cooperation Project of Ningbo (2016D10012), and 3315 Program of Ningbo.

\section{References}

[1] C. Christoglou, N. Voudouris, G. N. Angelopoulos, M. Pant, and W. Dahl, "Deposition of aluminium on magnesium by a CVD process," Surface and Coatings Technology, vol. 184, no. 2-3, pp. 149-155, 2004.

[2] C. S. Lin and W. J. Li, "Corrosion resistance of cerium-conversion coated AZ31 magnesium alloys in cerium nitrate solutions," Materials Transactions, vol. 47, no. 4, pp. 1020-1025, 2006.

[3] Z. Shao, Z. Cai, and J. Shi, "Preparation and performance of electroless nickel on AZ91D magnesium alloy," Materials and Manufacturing Processes, vol. 31, no. 9, pp. 1238-1245, 2015.

[4] R. F. Zhang and S. F. Zhang, "Formation of micro-arc oxidation coatings on AZ91HP magnesium alloys," Corrosion Science, vol. 51, no. 12, pp. 2820-2825, 2009.

[5] X. Zhong, Q. Li, B. Chen, J. Wang, J. Hu, and W. Hu, "Effect of sintering temperature on corrosion properties of sol-gel based $\mathrm{Al}_{2} \mathrm{O}_{3}$ coatings on pre-treated AZ91D magnesium alloy," Corrosion Science, vol. 51, no. 12, pp. 2950-2958, 2009.

[6] H. Altun and S. Sen, "The effect of DC magnetron sputtering AlN coatings on the corrosion behaviour of magnesium alloys," Surface and Coatings Technology, vol. 197, no. 2-3, pp. 193-200, 2005.

[7] M. Carboneras, M. D. López, P. Rodrigo et al., "Corrosion behaviour of thermally sprayed $\mathrm{Al}$ and $\mathrm{Al} / \mathrm{SiCp}$ composite coatings on ZE41 magnesium alloy in chloride medium," Corrosion Science, vol. 52, no. 3, pp. 761-768, 2010.

[8] E. Irissou, J. G. Legoux, B. Arsenault, and C. Moreau, "Investigation of $\mathrm{Al}-\mathrm{Al}_{2} \mathrm{O}_{3}$ cold spray coating formation and properties," Journal of Thermal Spray Technology, vol. 16, no. 5-6, pp. 661-668, 2007.

[9] Y. Tao, T. Xiong, C. Sun, H. Jin, H. Du, and T. Li, "Effect of $\alpha-\mathrm{Al}_{2} \mathrm{O}_{3}$ on the properties of cold sprayed $\mathrm{Al} / \alpha-\mathrm{Al}_{2} \mathrm{O}_{3}$ composite coatings on AZ91D magnesium alloy," Applied Surface Science, vol. 256, no. 1, pp. 261-266, 2009.
[10] H. Y. Lee, S. H. Jung, S. Y. Lee, Y. H. You, and K. H. Ko, "Correlation between $\mathrm{Al}_{2} \mathrm{O}_{3}$ particles and interface of $\mathrm{Al}-\mathrm{Al}_{2} \mathrm{O}_{3}$ coatings by cold spray," Applied Surface Science, vol. 252, no. 5, pp. 1891-1898, 2005.

[11] H. Y. Lee, Y. H. Yu, Y. C. Lee, Y. P. Hong, and K. H. Ko, “Cold spray of $\mathrm{SiC}$ and $\mathrm{Al}_{2} \mathrm{O}_{3}$ with soft metal incorporation: a technical contribution," Journal of Thermal Spray Technology, vol. 13, no. 2, pp. 184-189, 2004.

[12] A. Shkodkin, A. Kashirin, O. Klyuev, and T. Buzdygar, "Metal particle deposition stimulation by surface abrasive treatment in gas dynamic spraying," Journal of Thermal Spray Technology, vol. 15, no. 3, pp. 382-386, 2006.

[13] Q. Wang, K. Spencer, N. Birbilis, and M. X. Zhang, "The influence of ceramic particles on bond strength of cold spray composite coatings on AZ91 alloy substrate," Surface and Coatings Technology, vol. 205, no. 1, pp. 50-56, 2010.

[14] E. Sansoucy, P. Marcoux, L. Ajdelsztajn, and B. Jodoin, "Properties of SiC-reinforced aluminum alloy coatings produced by the cold gas dynamic spraying process," Surface and Coatings Technology, vol. 202, no. 16, pp. 3988-3996, 2008.

[15] G. Eesley, A. Elmoursi, and N. Patel, "Thermal properties of kinetic spray Al-SiC metal-matrix composite," Journal of Materials Research, vol. 18, no. 4, pp. 855-860, 2003.

[16] M. Yu, X. K. Suo, W. Y. Li, Y. Y. Wang, and H. L. Liao, "Microstructure, mechanical property and wear performance of cold sprayed Al5056/SiCp composite coatings: effect of reinforcement content," Applied Surface Science, vol. 289, pp. 188-196, 2014.

[17] H. Lee and K. Ko, "Effect of SiC particle size on cold sprayed Al-SiC composite coatings," Surface Engineering, vol. 25, no. 8, pp. 606-611, 2013.

[18] W. Y. Li, G. Zhang, H. L. Liao, and C. Coddet, "Characterizations of cold sprayed TiN particle reinforced Al2319 composite coating," Journal of Materials Processing Technology, vol. 202, no. 1-3, pp. 508-513, 2008.

[19] W. Y. Li, G. Zhang, C. Zhang, O. Elkedim, H. Liao, and C. Coddet, "Effect of ball milling of feedstock powder on microstructure and properties of TiN particle-reinforced $\mathrm{Al}$ alloy-based composites fabricated by cold spraying," Journal of Thermal Spray Technology, vol. 17, no. 3, pp. 316-322, 2008.

[20] T. H. Van Steenkiste, J. R. Smith, and R. E. Teets, "Aluminum coatings via kinetic spray with relatively large powder particles," Surface and Coatings Technology, vol. 154, pp. 237-252, 2002.

[21] E. Irissou, J. G. Legoux, A. N. Ryabinin, B. Jodoin, and C. Moreau, "Review on cold spray process and technology: part I-intellectual property," Journal of Thermal Spray Technology, vol. 17, no. 4, pp. 495-516, 2008.

[22] S. Yin, Y. C. Xie, J. Cizek et al., "Advanced diamond-reinforced metal matrix composites via cold spray: properties and deposition mechanism," Composites Part B-Engineering, vol. 113, pp. 44-54, 2017.

[23] M. Yu, W. Y. Li, X. K. Suo, and H. L. Liao, "Effects of gas temperature and ceramic particle content on microstructure and microhardness of cold sprayed $\mathrm{SiCp} / \mathrm{Al} 5056$ composite coatings," Surface and Coatings Technology, vol. 220, pp. 102-106, 2013.

[24] W. Sun, A. W. Y. Tan, I. Marinescu, E. J. Liu, and ASME, Effects of Surface Roughness on Bonding Behavior of Cold Spray TI6AL4V Coatings, American Society of Mechanical Engineers, New York, NY, USA, 2017.

[25] S. Kumar, G. Bae, and C. Lee, "Influence of substrate roughness on bonding mechanism in cold spray," Surface and Coatings Technology, vol. 304, pp. 592-605, 2016. 
[26] Y. S. Zoo, J. W. An, D. P. Lim, and D. S. Lim, "Effect of carbon nanotube addition on tribological behavior of UHMWPE," Tribology Letters, vol. 16, no. 4, pp. 305-309, 2004.

[27] R. G. Kelly, J. R. Scully, D. W. Shoesmith, and R. G. Buchheit, "Electrochemical techniques in corrosion science and engineering," Chemphyschem, vol. 4, pp. 296-298, 2003.

[28] S. T. Aruna, V. Ezhil Selvi, V. K. William Grips, and K. S. Rajam, "Corrosion- and wear-resistant properties of $\mathrm{Ni}-\mathrm{Al}_{2} \mathrm{O}_{3}$ composite coatings containing various forms of alumina," Journal of Applied Electrochemistry, vol. 41, no. 4, pp. 461-468, 2011. 


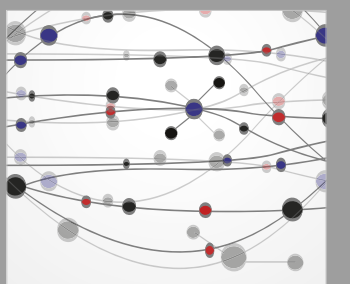

The Scientific World Journal
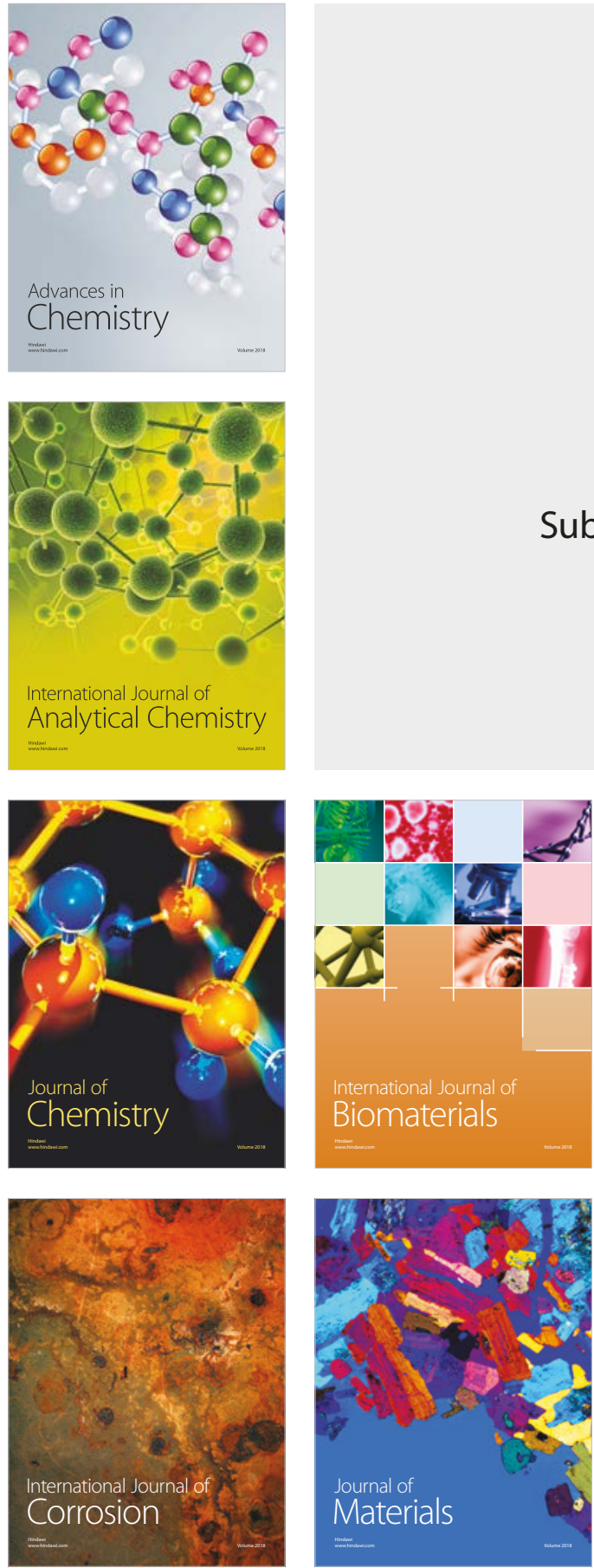

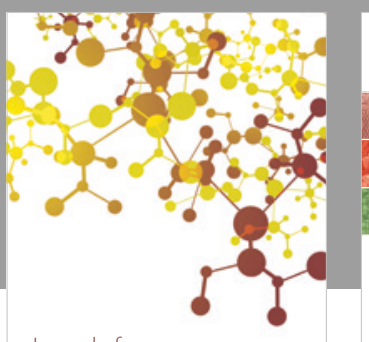

Journal of

Applied Chemistry
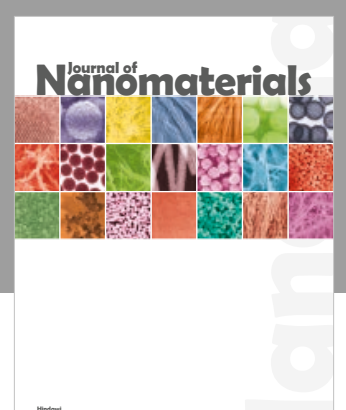

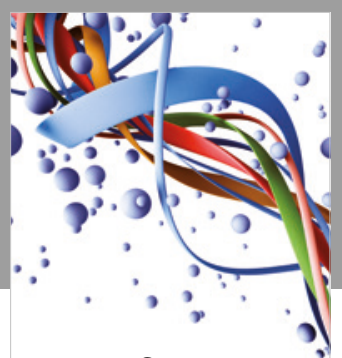

Scientifica

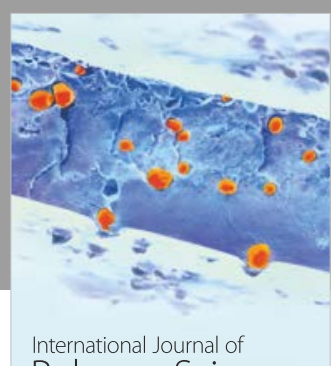

Polymer Science

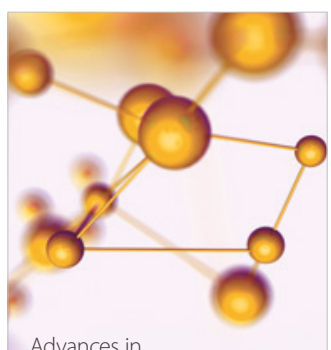

Physical Chemistry
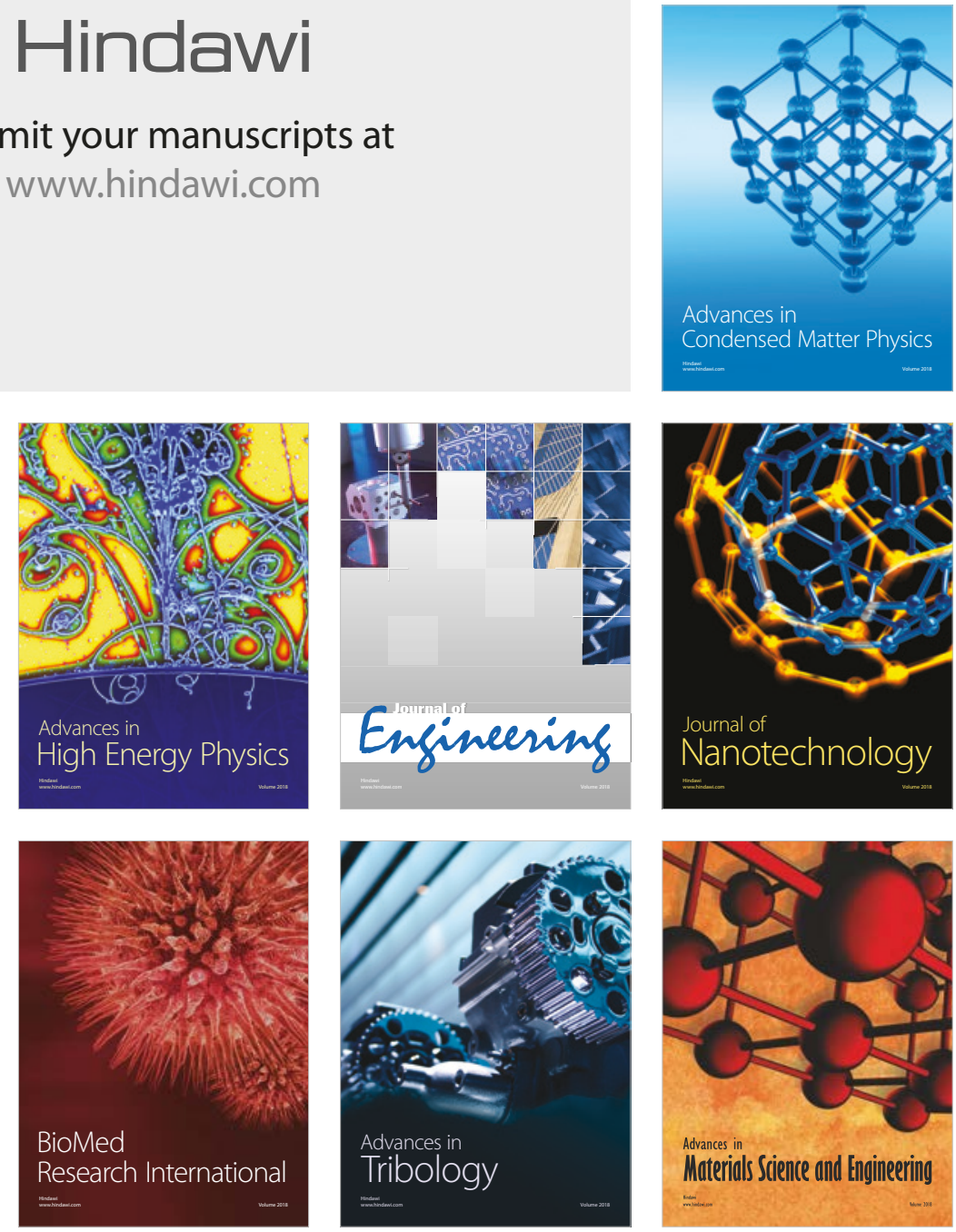